\title{
Motivational Regulations and Goal Orientation in Division III Basketball Players: Gender and Playing Status Differences
}

\author{
Teri J. Hepler (Corresponding author) \\ Department of Exercise and Sport Science, University of Wisconsin- La Crosse, 1725 State St. La Crosse, WI, USA \\ E-mail: thepler@uwlax.edu \\ Kelly S. Witte \\ Department of Health, Physical Education, Recreation and Coaching, University of Wisconsin- Whitewater, 800 W. Main St., Whitewater, WI, USA \\ E-mail: wittek@uww.edu
}

Received: 11-02-2016

Accepted: 19-04-2016

Published: 30-04-2016

doi:10.7575/aiac.ijkss.v.4n.2p.62

URL: http://dx.doi.org/10.7575/aiac.ijkss.v.4n.2.p.62

\begin{abstract}
Objective: The purpose of this study was to examine differences in motivational regulations and goal orientation based on gender and playing status. Method: Two hundred and fourteen Division III basketball players (92 males, 112 females) completed the Sport Motivation Scale-28 and the Task and Ego Orientation in Sport. Based on average playing time per game, participants were classified as starters (over 20 minutes, $n=80)$, substitutes $(6-20$ minutes, $n=$ 65 ), and benchwarmers (5 minutes or less, $n=63$ ). Results: Results indicated that males scored higher than females on external regulation, substitutes scored higher than starters on all 3 dimensions of extrinsic motivation, and benchwarmers expressed the most amotivation. Task orientation was positively related to all types of intrinsic and extrinsic motivation. Conclusion: While coaches should strive to enhance the intrinsic motivation in all of their athletes, special emphasis should be placed on promoting intrinsic motivation of male athletes and substitutes.
\end{abstract}

Keywords: motives, playing time, sex differences

\section{Introduction}

Motivation is an important psychological factor that can influence participation, effort, and persistence in sport. One framework that has helped enhance our understanding of motivation is self-determination theory (SDT; Deci \& Ryan, 1985; Ryan \& Deci, 2000, 2002). SDT outlines three forms of motivation that vary in the degree of self-determination. The most self-determined form is intrinsic motivation (IM). IM refers to participating in an activity for the inherent pleasure, satisfaction, and enjoyment of the activity. Participating in a sport because it is challenging or exciting is an example of IM. Extrinsic motivation (EM) represents engaging in a behavior in order to achieve an instrumental purpose (i.e., a means to an end). A college athlete who plays a sport in order to keep a scholarship is extrinsically motivated. The last form of motivation is amotivation. Amotivation reflects a lack of intention toward action and is essentially the absence of IM and EM (Deci \& Ryan, 1985; Ryan \& Deci, 2000, 2002).

Moreover, IM and EM can be further broken down into different types. IM comprises three different categories: IM- to know (e.g., learning, discovery), IM- to accomplish (e.g., mastery, creativity), and IM- to experience stimulation (e.g., fun, excitement). There are four different types of EM with each type varying in the degree of self-determination. The most self-determined type of EM is integrated regulation, which refers to participating in an activity because it is aligns with a person's basic goals and values. Another self-determined type of EM is identified regulation whereby a person chooses to engage in activity because the behavior is valued. Behavior that is performed due to internal pressures such as guilt and shame reflects introjected regulation (Ryan \& Deci, 2000). External regulation involves controlling behavior through external sources, such as receiving rewards (e.g., praise, scholarships) or avoiding negative consequences (e.g., criticism, punishments) (Pelletier et al., 1995). All types of IM, as well as integrated and identified regulation, reflect self-determined behavior whereas all remaining categories (introjected regulation, external regulation, and amotivation) are externally controlled (i.e., non-self-determined). SDT purports that fulfilling one's basic psychological needs for autonomy (control over one's actions), competence (demonstrate ability), and relatedness (social relationships and connectedness) serve to enhance IM (Ryan \& Deci, 2002). Likewise, experiences that fail to satisfy these needs can undermine IM. IM is linked with various positive outcomes such as increased effort, more positive affect, better sportspersonship, greater learning, and lower performance-related anxiety (Vallerand, 1997; Vallerand \& Losier, 1999). Moreover, amotivation is negatively related to satisfaction, perceived control, and wellbeing (Ryan \& Deci, 2000).

In addition to SDT, achievement goal theory (AGT, Nicholls, 1989) has also been instrumental in advancing our understanding of motivation in sport. AGT focuses on how people define success and competence and suggests that there are two distinct goal orientations: task orientation and ego orientation. A task-oriented individual defines success 
and competence using self-referenced criteria such as improvement, mastery, and effort. Conversely, someone who is ego-oriented gauges success based on normative comparisons, such as winning or outperforming others. Task orientation is associated with adaptive behaviors, such as persistence, effort, enjoyment, and interest. Conversely, a high ego orientation combined with low perceived competence is often related to maladaptive behaviors such as task avoidance, low persistence, and little effort (Roberts, 2012). It is important to understand that task and ego orientations are separate, distinct constructs in which a person can express some degree of each orientation.

\subsection{Linking SDT and AGT Theories}

SDT and AGT provide unique perspectives on motivation, but it has been suggested that the two theories are related. Ntoumanis (2001) posited that goal orientation influences IM through the satisfaction of the psychological needs for competence, autonomy, and relatedness. Specifically, a task orientation is predicted to enhance IM because this goal orientation is likely to fulfill these psychological needs on a consistent basis. Similarly, as a high ego orientation focuses on external factors such as expected outcomes, rewards, and social approval, it could undermine selfdetermined motivation and encourage the adoption of non-self-determined motivational regulations. In an empirical test of these assertions, task orientation was found to be a significant and positive predictor of self-determined types of motivation whereas ego orientation was positively related to the externally controlled sources of introjected regulation and external regulation (Ntoumanis, 2001). More recently Chin and colleagues (2012) found similar results, with task orientation most strongly associated with IM, and ego orientation related to EM and amotivation.

\subsection{Gender Differences}

Previous research on motivational regulations and goal orientation in sport has revealed some common gender differences. In general, males are more extrinsically motivated (Chin, Khoo, \& Low, 2012; Cremades, Flournoy, \& Gomez, 2012; Fortier, Vallerand, Briére, \& Provencher, 1995; Pelletier et al., 1995; Symons Downs, Savage, \& DiNallo, 2013) and have a stronger ego goal orientation than females (Anderson \& Dixon, 2009; Bakirtzoglou \& Ioannu, 2012; Chin et al., 2012; Li, Harmer, \& Acock, 1996; Lochbaum, Bixby, \& Wang, 2007; Moreno-Murcia, Sicilia, Cervelló, Huéscar, \& Dumitru, 2011; Ntoumanis, 2001). Likewise, compared to males, females typically report more self-determined types of motivation (Amorose \& Anderson-Butcher, 2007; Chantal, Guay, Dobreva-Martinova, \& Vallerand, 1996; Cremades et al., 2012; Ruiz-Juan \& Sancho, 2012) and are more task-oriented (Anderson \& Dixon, 2009; Hanrahan \& Biddle, 2002; Hanrahan \& Cerin, 2009). However, these are general characterizations and some studies have reported contrary findings. For example, a few studies have found males to demonstrate more selfdetermined motivation than females (Chin et al., 2012; Ntoumanis, 2001; Symons Downs et al., 2013). Likewise, some research has found no significant gender differences on goal orientation (Abrahamsen, Roberts, \& Pensgaard, 2008; Cumming, Hall, Harwood, \& Gammage, 2002).

\subsection{Playing Status Differences}

In addition to gender, motivational differences based on playing status variables such as scholarships, performance, and playing time have also been examined. Previous research suggests that athletes with a higher playing status (i.e., scholarship athletes, title/medal winners, starters and primary substitutes) tend to be less motivated by self-determined factors (Chantal et al., 1996; Cremades et al., 2012; Ryan, 1977; Ryan, 1980) and have a stronger mastery goal orientation (Petlichkoff, 1993a; Petlichkoff, 1993b) than athletes of a lower playing status (i.e., non-scholarship, nontitle/medal holders). It should be noted that some studies have found no significant differences between high and low playing status athletes on motivational regulations (Blegen, Stenson, Micke, \& Matthews, 2012) or participation motivation (Weiss \& Frazer, 1995).

\subsection{Rationale for the Study}

What motivates or drives athletes to participate in college athletics is an important question for coaches, athletes, and sport psychologists alike. As described above, much of the previous research exploring gender and playing status differences on motivational regulations and goal orientation has yielded mixed results. A potential explanation for these inconsistent findings may be due to differences in participant ages, types of sports, and competition level in previous research (Hanrahan \& Cerin, 2009). Therefore, the purpose of this study was to explore the motivational regulations and achievement goal orientation of male and female National Collegiate Athletic Association (NCAA) Division III basketball players. In this manner, the current study follows the suggestions of Hanrahan and Cerin (2009) by examining similarly aged males and females competing in the same sport at the same competitive level. While there has been a considerable amount of research on the motivation of youth and NCAA Division I athletes, less is known about what motivates NCAA Division III athletes to practice and compete on a daily basis. There are several reasons why it is important to examine these constructs at the Division III level. First, Division III represents the largest division in the NCAA with over 184,000 participants representing approximately 450 different schools (National Collegiate Athletic Association, 2014). Division III is also unique because, unlike Division I and Division II, the athletes do not receive any athletic scholarships or monetary compensation for their involvement in intercollegiate athletics. As a consequence of better understanding these motivational constructs, coaches can tailor their practices to better suit each individual thereby enhancing the learning, performance, enjoyment, satisfaction, and retention of these athletes.

In order to explore the motivation of Division III basketball players, the current study examined two separate research questions: 
Research Question 1: Are there differences in athletes' motivational regulations and achievement goal orientation based on gender or playing status?

Research Question 2: Does achievement goal orientation influence athletes' motivational regulations?

\section{Methods}

\subsection{Participants}

Two hundred and fourteen NCAA Division III basketball players (92 males, 122 females) participated in the study. On average, participants were $20.10(\mathrm{SD}=1.30)$ years old and had $2.31(\mathrm{SD}=1.13)$ years of collegiate basketball playing experience. The sample included 60 first year players, 58 sophomores, 47 juniors, and 45 seniors.

\subsection{Instrumentation}

\subsubsection{Sport Motivation Scale-28 (SMS-28)}

The Sport Motivation Scale-28 was used to assess participants' motivational regulations (Pelletier et al., 1995). This 28 -item questionnaire assesses various reasons for which a person currently participates in his or her sport. Participants responded to the stem "Why do you practice your sport" using a 7-point Likert scale $(1=$ does not correspond at all; $7=$ corresponds exactly). The SMS-28 has 7 subscales, each comprising 4 items, corresponding with the following types of IM and EM: IM-to know (e.g., pleasure of discovering new training techniques), IM-to accomplish (e.g., satisfaction I experience when perfecting my abilities), IM-to experience stimulation (e.g., pleasure I feel in living exciting experiences), identified regulation (e.g., it is one of the best ways I have chosen to develop other aspects of myself), introjected regulation (e.g., I must do sports to feel good about myself), external regulation (e.g., for the prestige of being an athlete), and amotivation (e.g., it is not clear to me anymore). The SMS-28 has been widely used in motivation research and has been shown to have adequate internal consistency and construct validity (Pelletier, Vallerand, \& Sarazin, 2007). In the current study, Cronbach's alpha for each of the subscales ranged from .67 (introjected regulation) to .86 (amotivation). With the exception of introjected regulation, all subscales met the minimum criteria (.70) for acceptable internal consistency (Nunnally \& Bernstein, 1994).

\subsubsection{Task and Ego Orientation in Sport Questionnaire (TEOSQ).}

Participants' achievement goal orientation was measured by the Task and Ego Orientation in Sport Questionnaire (TEOSQ) (Duda, 1989). The TEOSQ measures task (7 items) and ego (6 items) orientation in sport. The questionnaire instructed participants to reflect upon a time when they felt most successful in sport and indicate their agreement $(1=$ strongly disagree, $5=$ strongly agree) for each of the 13 items. Example questions included "I feel successful in sport when I am the only one who can do the play or skill" (ego orientation) and "I feel successful in sport when I learn a new skill by trying hard" (task orientation). Previous research has found the TEOSQ to have acceptable validity and reliability (Duda \& Whitehead, 1998). Cronbach's alphas for the ego (.79) and task (.75) subscales demonstrated acceptable internal consistency (Nunnally \& Bernstein, 1994).

\subsection{Procedure}

The institutional review board associated with the second author's university approved all procedures and instruments. During the last month of the regular season, a researcher contacted the head men's and women's Division III basketball coaches from approximately 15 universities in the Midwest. Most of the schools were members in the Wisconsin Intercollegiate Athletic Conference or represented other similar institutions in the Midwest. The coaches were asked to forward an e-mail containing a survey link to all of the members of their team. Athletes who wished to participate in the study simply clicked on the link contained in the e-mail and were directed to the online surveys. Participation in the study was voluntary and it took approximately 15 minutes to complete the various questionnaires.

\subsection{Data Analysis}

Research Question 1 was examined using a 2x3 (Gender x Playing Status) MANOVA, while Research Question 2 was explored through multiple regression analyses. Assumptions such as normality, linearity, and homogeneity were met for all analyses (Tabachnick \& Fidell, 2001).

\section{Results}

\subsection{Descriptive Statistics}

Prior to conducting the study, 3 playing status categories were operationally defined based on average playing time throughout the entire regular season. Specifically, a starter was defined as a player who averaged over 20 minutes a game (i.e., played more than $50 \%$ of minutes per game, on average). Athletes who played between 6 and 20 minutes a game were labeled substitutes. Benchwarmers were those players who averaged fewer than 5 minutes a game. Based on the self-reported average minutes played per game, participants were classified as starters $(n=80 ; 46$ females, 34 males), substitutes ( $\mathrm{n}=65 ; 37$ females, 28 males), and benchwarmers $(\mathrm{n}=63 ; 38$ females, 24 males). It is important to note that the operational definitions for starter, substitute, and benchwarmer used in this study may not correspond with every athlete's actual role on the team. For example, it is possible for a key player who comes off the bench (i.e., a substitute) to average more than 20 minutes a game and therefore be classified as a starter for the purposes of the study. In terms of collegiate playing experience, starters averaged 2.95 years $(S D=1.07)$, substitutes reported 2.21 years $(S D$ $=1.02)$, while benchwarmers had the least experience $(M=1.57, S D=0.83)$. Overall, participants $(N=214)$ exhibited 
a higher task orientation $(M=4.18, S D=.46)$ than their ego orientation $(M=3.07, S D=.77)$. Likewise, the athletes reported higher levels of self-determined motivation (IM- to know $M=4.15, S D=1.21$; IM- to accomplish $M=5.01$, $S D=1.03$; IM- to stimulate $M=5.18, S D=1.07$; identified regulation $M=4.54, S D=1.17$ ) and lower levels of externally controlled behavior (introjected regulation $M=3.43, S D=1.28$; external regulation $M=3.56 ; S D=1.27$ ). Amotivation was relatively low $(M=1.90, S D=1.22)$.

\subsection{Main Analyses}

A 2x3 (Gender x Playing Status) MANOVA examined differences in motivational regulations and goal orientation based on gender, playing status, and the interaction of gender and playing status. Results indicated significant main effects of gender (Wilks' $\lambda=.846, F(9,141)=2.86, p=.004$, partial $\eta^{2}=.154$ ) and playing status (Wilks' $\lambda=.735, F(18,282)=$ $2.60, p<.001$, partial $\left.\eta^{2}=.143\right)$. The gender $x$ playing status interaction was not significant, Wilks' $\lambda=.892 F(18,282)$ $=0.93, p=.547$, partial $\eta^{2}=.056$. In terms of gender differences, males reported significantly higher ego orientation $\left(F(1,149)=5.23, p=.023\right.$, partial $\eta^{2}=.034$ and external regulation than females, $F(1,155)=4.02, p=.047$, partial $\eta^{2}=$ .020). In terms of motivational regulations, significant differences based on playing status were found on 5 out of the 7 motivation subscales: IM-to know $\left(F(2,155)=3.29, p=.040\right.$, partial $\left.\eta^{2}=.042\right)$, identified regulation $(F(2,155)=4.17$, $p=.017$, partial $\left.\eta^{2}=.053\right)$, introjected regulation $\left(F(2,155)=6.03, p=.003\right.$, partial $\left.\eta^{2}=.075\right)$, external regulation $(F(2$, $155)=3.96, p=.021$, partial $\eta^{2}=.050$, and amotivation $\left(F(2,155)=6.92, p=.001\right.$, partial $\eta^{2}=.085$. Post hoc tests revealed that substitutes scored higher than the starters on all 3 categories of extrinsic motivation. In addition, benchwarmers expressed higher levels of amotivation than did starters or substitutes. Tables 1 and 2 present means and standard deviations for goal orientation (Table 1) and motivation subscales (Table 2) according to gender and playing status.

Table 1. Mean goal orientation based on gender and playing status

\begin{tabular}{llllll}
\hline & \multicolumn{2}{c}{ Gender M (SD) } & \multicolumn{3}{c}{ Playing Status M (SD) } \\
Goal Orientation & Males & Females & Starters & Substitutes & Benchwarmers \\
\hline Task & $4.15(0.54)$ & $4.19(0.41)$ & $4.07(0.51)$ & $4.23(0.42)$ & $4.27(0.43)$ \\
Ego & $3.25(0.73)^{*}$ & $2.94(0.78)$ & $2.99(0.78)$ & $3.08(0.82)$ & $3.11(0.76)$ \\
\hline
\end{tabular}

$* \mathrm{p}<.05$

Table 2. Mean motivational regulations based on gender and playing status

\begin{tabular}{llllll}
\hline & \multicolumn{2}{c}{ Gender M (SD) } & \multicolumn{3}{c}{ Playing Status M (SD) } \\
Motivation subscale & Males & Females & Starters & Substitutes & Benchwarmers \\
\hline IM- to know & $4.29(1.37)$ & $4.02(1.11)$ & $3.91(1.22)$ & $4.16(1.20)$ & $4.42(1.23)$ \\
IM- to accomplish & $5.12(1.04)$ & $4.94(1.04)$ & $4.88(0.98)$ & $5.10(1.19)$ & $5.11(0.96)$ \\
IM- to stimulate & $5.29(1.02)$ & $5.15(1.09)$ & $5.18(1.00)$ & $5.18(1.11)$ & $5.28(1.11)$ \\
Identified regulation & $4.35(1.18)$ & $4.67(1.12)$ & $4.22(1.15)^{*}$ & $4.77(1.12)^{*}$ & $4.71(1.14)$ \\
Introjected regulation & $3.46(1.34)$ & $3.39(1.23)$ & $2.99(1.07)^{*}$ & $3.75(1.35)^{*}$ & $3.57(1.27)^{*}$ \\
External regulation & $3.81(1.40)^{*}$ & $3.43(1.17)^{*}$ & $3.26(1.10)^{*}$ & $3.84(1.32)^{*}$ & $3.67(1.38)$ \\
Amotivation & $1.79(1.14)$ & $1.94(1.21)$ & $1.54(0.79)^{*}$ & $1.79(0.98)^{*}$ & $2.34(1.50)^{*}$ \\
\end{tabular}

IM: intrinsic motivation; $* \mathrm{p}<.05$

The second objective investigated the influence of goal orientation on motivational regulations. Specifically, a series of multiple regressions were carried out, with task and ego orientation as the predictor variables and each subscale of the SMS serving as the criterion variables. Task orientation was significantly and positively related to all types of IM and EM. However, the standardized betas suggested that task orientation was most strongly related to self-determined types of motivation. Ego orientation was a significant negative predictor of all 3 types of IM. Additionally, ego orientation was positively related to external regulation. See Table 3 for complete results of the regression analysis.

Due to the numerous differences in goal orientation and motivational regulations based on gender and playing status, it was necessary to examine if the relationships between task and ego orientation with the SMS subscales varied among these different groups. Accordingly, another set of regressions were conducted which included gender and playing status dummy variables, along with the resulting interactions with task and ego orientation. The only significant difference based on gender was the relationship between task orientation and amotivation, $F(11,148)=3.80, p<.001$, 
$R^{2}=.220$. The slope for males was steep and negative whereas the relationship for females was very slightly positive $(\beta=-1.65, t(48)=-2.49, p=.014)$. In terms of playing status, results indicated that the regression slopes were similar for all 3 playing status groups on all types of motivation, except for introjected regulation $(F(11,148)=2.58, p=.005$, $\left.R^{2}=.161\right)$. Specifically, the slope between task orientation and introjected regulation was steeper and more positive for benchwarmers as compared to starters, $\beta=-1.80, t(48)=-2.22, p=.028$.

Table 3. Regression analysis predicting motivation from goal orientation

\begin{tabular}{lccccccccc}
\hline & \multicolumn{3}{c}{ Ego goal orientation } & \multicolumn{3}{c}{ Task goal orientation } \\
\hline Motivation subscale & $\mathrm{B}$ & SE B & $\beta$ & $p$-value & $\mathrm{B}$ & SE B & $\beta$ & $p$-value \\
IM- to know & -.271 & .107 & -.171 & .012 & 1.40 & .180 & .526 & .000 \\
IM- to accomplish & -.303 & .093 & -.226 & .001 & 1.046 & .158 & .461 & .000 \\
IM- to stimulate & -.318 & .102 & -.230 & .002 & .807 & .171 & .348 & .000 \\
Identified regulation & -.153 & .111 & -.130 & .169 & .893 & .188 & .355 & .000 \\
Introjected regulation & .107 & .127 & .066 & .401 & .550 & .215 & .199 & .012 \\
External regulation & .451 & .120 & .281 & .000 & .502 & .203 & .185 & .014 \\
Amotivation & .192 & .120 & .123 & .111 & -.208 & .202 & -.082 & .304 \\
\end{tabular}

IM: intrinsic motivation

\section{Discussion}

Based on the results of this study, there are several general conclusions that can be reached about the relationships between gender, playing status, motivational regulations, and goal orientation. First, there are slight differences between males and females on motivational regulations and goal orientation. However, these gender differences are small and should be interpreted in the broader context of each athlete's overall motivation profile. For instance, males were found to score significantly higher on external regulation than females. This finding supports previous research suggesting that males tend to have higher extrinsic motivation as compared to females (e.g., Chin et al., 2012; Cremades et al., 2012). While Division III sports lack athletic scholarships, there are certainly other external rewards associated with sports participation and performance, such as media recognition, social status, praise, and social approval, which may affect the motivation of males and females differently. For example, previous research has revealed that men's sports receive more media coverage than women's sports (Billings \& Eastman, 2003; Grappendorf, Henderson, Sanders, \& Peel, 2009). While the media attention itself may be a major motivating factor, it would also likely increase other external rewards such as social status, prestige, peer approval, etc. In this manner, the external rewards for males may be greater than they are for females. This result should be interpreted with caution, as the effect size (partial $\eta^{2}=$ .020) for this difference was rather small and may hold little practical significance. It should also be noted that males reported higher scores for self-determined motivation as compared to non-self-determined types.

Gender differences were also found on ego orientation, with males placing more emphasis on outperforming others than did females. This finding supports previous research reporting gender differences on ego orientation, but not task orientation (Gill, Kelley, Martin, \& Caruso, 1991; Li et al., 1996). One factor that may contribute to this difference is perceived motivational climate. Previous research has demonstrated that males perceive a more ego-involving climate than females (Bakirtzoglou \& Ioannu, 2012; Moreno-Murcia et al., 2011) and that motivational climate can influence goal orientation (Saotome, Harada, \& Nakamura, 2012). As this effect size was small (partial $\eta^{2}=.034$ ), it is important to consider ego orientation in conjunction with task orientation. In the current study, males expressed a much stronger task goal orientation than they did an ego orientation. In other words, males placed more emphasis on mastery and improvement than they did on winning. As the nature of sport is competitive, and the effects of task and ego orientation are somewhat additive, it could be argued that the males, with a high task and high ego orientation, demonstrated a very adaptive goal orientation.

A second general conclusion is that playing status has a moderate impact on the motivational regulations of Division III male and female basketball players. Of particular note is that substitutes were much more extrinsically motivated than starters. This finding is inconsistent with previous research reporting that more successful athletes (e.g., scholarship, title/medal holders) have higher levels of non-self-determined motivation than less successful athletes (e.g., nonscholarship, non-title/medal holders). The differences in the findings may be due to the competitive level of the study participants (i.e., elite Division I level, national, or international levels as compared to non-elite Division III). Division III athletics lack many of the major external rewards and pressures of elite competition, such as scholarships, Olympic medals, fame, potential multimillion dollar contracts, intense performance scrutiny, etc. For athletes at the Division III level, playing time may be seen as the main external reward. In turn, extensive playing time may lead to other external rewards such as media attention, public recognition, social status, and peer approval. In the current study, the starters 
have already earned significant playing time. However, while the substitutes certainly play an important role in their team's performance, they have yet to break into the top tier roles on the team. In this manner, substitutes may perceive a great deal of intrateam competition whereby they are very motivated to outplay the player(s) ahead of them in order to earn more playing time and the associated external rewards. In support of this notion, previous research has found that competition can increase EM (Fortier et al., 1995).

One final conclusion is that goal orientation is clearly related to motivational regulations and these relationships vary among the different types of motivation. According to the results, task orientation was a significant and positive predictor of all 4 types of self-determined motivation. This replicates the findings of Ntoumanis (2001) and suggests that task-oriented individuals participate for intrinsic reasons, such as learning new things, improving existing skills, or having fun. Moreover, the current study also found that ego orientation had a negative association with IM. Based on SDT and the work of Ntoumanis (2001), task goal orientation may enhance IM by fulfilling the psychological needs of autonomy, competence, and relatedness whereas an ego orientation may undermine IM by failing to consistently satisfy these needs.

In terms of the association between goal orientation and motivational regulations, an interesting finding that is contrary to previous research is that task orientation was a significant and positive predictor of introjected regulation and external regulation (Brunel, 1999; Ntoumanis, 2001). In this manner, participants whose goal orientation focused mainly on mastery and improvement also exhibited high levels of non-self-determined motivation. One possible explanation of these findings may be related to the interaction of task and ego orientation. As previously described, task and ego orientations are separate constructs in which a person can be high on both, low on both, or high on one and low on the other. For instance, Ntoumanis (2001) reported that task and ego orientations interacted to determine one's external regulation. Specifically, a high task orientation combined with a high ego orientation was associated with higher levels of external regulation, as compared to participants with a high task, low ego orientation. The present study did not explore interactions between goal orientations, but it is possible that this interaction played a role in the results. Another plausible explanation relates to the competitive nature of sport. In sport, success is met with a variety of external rewards, such as positive feedback, awards, public recognition, and approval (i.e., external regulation). Likewise, good performances often serve to enhance one's pride or self-esteem (i.e., introjected regulation). In other words, a person who is intrinsically driven to participate in an activity may also be further motivated by external factors. In essence, this finding represents that athletes derive motivation from multiple intrinsic and extrinsic sources.

Moreover, the study also examined interactions between gender and playing status on the relationship between AGT and SDT. The results suggested that males with a high task orientation had lower levels of amotivation than males with a lower task orientation, whereas the same trend was not observed among females. Perhaps the best way to understand this result is to consider both task and ego orientation. In the current study, males were found to score high on both task and ego orientation, whereas females scored high on task and lower on ego orientation. For males, a high task orientation may counter the potential ill effects of a high ego orientation and thereby reduce amotivation. As females in general do not have a high ego orientation, the same protective effect of a higher task orientation is not needed nor observed. For instance, Chin and colleagues (2012) reported that males had higher levels of amotivation than females. They proposed that males who struggled to meet performance-based expectations, either extrinsic or self-imposed (i.e., high ego orientation), would be amotivated. In this manner, it is likely that also defining one's competence in terms of mastery, effort, and ability (i.e., task orientation) might prevent a state of amotivation that could result from failing to meet one's ego goals. In support of this, Anderson and Dixon (2009) posited that a "person high on ego orientation and low on task orientation is more likely to be the least satisfied and least motivated participant." (p. 61).

In terms of playing status, the relationship between task orientation and introjected regulation was stronger and more positive for benchwarmers as compared to starters. In others words, a player who receives little-to-no playing time who has a high task orientation may be motivated to participate in Division III college basketball by internal pressures to achieve rewards (e.g., enhance self-esteem, experience pride) or avoid punishments (e.g., guilt, shame). For instance, benchwarmers may feel a sense of self-worth simply by making the team or be driven by the feeling that they "ought" to play. For instance, after being superior high school players, benchwarmers in college sports can be particularly susceptible to a loss of identify (Rotella \& Newburg, 1989). Trying to maintain and protect this identity could be a motivating factor for benchwarmers. Social relationships may also be a strong source of introjected regulation for benchwarmers. One study found that the decision to participate in sport may be in part governed by the desire to establish or maintain social bonds (Gillison, Osborn, Standage, \& Skevington, 2009). In the absence of other major external rewards, such as playing time, media attention, and prestige, the social relationships with teammates may be a powerful motivator for benchwarmers.

\subsection{Implications for Practice}

A key to getting the best performance out of athletes is to understand what motivates them. Results of the current study suggest that coaches and sport psychologists should consider gender and playing status when implementing strategies aimed at enhancing motivation. As mentioned previously, self-determined types of motivation are linked to positive outcomes, such as increased effort and learning, and therefore coaches should strive to enhance the IM of all of their athletes. While coaches should strive to build self-determined motivation for all their athletes, results of the current study suggest that coaches should pay special attention to the self-determined motivation of substitutes and males. Coaches can enhance self-determined motivation by creating a motivational climate that fulfills the needs for autonomy, 
competence, and relatedness. For instance, providing opportunities for athletes to be successful, especially on challenging tasks, can enhance competence. Additionally, coaches can promote relatedness through team-building activities and developing personal relationships with their athletes that are not related to sport. Autonomy-supportive behaviors, which allow athletes the opportunity for choice and to be self-determining, have been the focus of a great deal of previous research. For instance, Mageau and Vallerand (2003) identified the following 7 autonomy-supportive behaviors: (1) provide choice, within set boundaries and rules; (2) explain rationale for tasks and rules; (3) acknowledge others' feelings and perspectives; (4) allow individuals the opportunity to work independently and exercise initiative; (5) provide non-controlling competence feedback; (6) avoid controlling feedback and use of tangible rewards; and (7) discourage ego-involvement. Research in sport and physical activity has found that autonomysupportive coaching behaviors can enhance autonomous types of motivation in athletes (Almagro, Sáenz-López, \& Moreno, 2010; Banack, Sabastion, \& Bloom, 2011; Fenton, Duda, Quested, \& Barret, 2014). Moreover, one study suggested that promoting autonomy could also enhance performance in sport (Spray, Wang, Biddle, \& Chatzisarantis, 2006). While these recommendations may help to enhance the self-determined motivation of all athletes, they may be especially useful for males and substitutes who tend to be more extrinsically motivated.

A second practical implication of this study relates to the relationship between goal orientation and motivation. In the current study, it was found that task goal orientation was most strongly related to self-determined motivation. Goal orientation is not a fixed trait, but rather one that is malleable to various external influences, including the perceived motivational climate created by the coach. A task-involving climate emphasizes the process of learning and improvement (Ames, 1992), such as focusing on effort and skill improvement and cooperating with teammates (Newton, Duda, \& Yin, 2000). A task-involving climate can enhance the task orientation of athletes (Gano-Overway \& Ewing, 2004; Saotome, Harada, \& Nakamura, 2012). One tool coaches may find useful to help create a task-involving motivational climate is TARGET. TARGET stands for Task (design of tasks), Authority (location of decision-making), Recognition (reward distribution), Grouping (criteria used to create groups), Evaluation (standards for performance) and Time (pace of learning) (Ames, 1992). Coaches can create a perceived task-involving climate by providing challenging and diverse tasks, allowing athletes opportunities for choice and leadership, providing recognition to individuals in private, creating mixed-ability groups, evaluating performance based on skill mastery and improvement, and adjusting time frames to accommodate individual differences in pace of learning. A task-involving motivational climate created by TARGET has been reported to be associated with positive cognitive, affective, and behavioral outcomes (Braithwaite, Spray \& Warburton, 2011).

\subsection{Limitations and Future Directions}

When interpreting the results of the current study, it is important to recognize the limitations of the study. One limitation that may have influenced the results is that only playing time, not performance, was used to operationally define the playing status groups. This could influence the results because performance may have a major impact on motivation, especially through perceptions of competence. For example, a young benchwarmer (i.e., plays less than 5 minutes a game) may play really well during those limited minutes of playing time thereby satisfying the need for competence and enhancing IM. Conversely, a starter who may be having a lackluster season may lack confidence and motivation. Additionally, the current study used average playing time over the course of a season, as opposed to recent playing time, to determine playing status groups. However, it is likely that many players may have changed status throughout the course of the season. For example, a player who is a starter in the early season may begin to struggle and be relegated to a substitute role later in the season or a young benchwarmer may improve and earn significantly more playing time at the end of the season. Another limitation of the study to consider is the use of the SMS-28 to measure motivational regulations. While the SMS-28 has been used extensively in previous research, it lacks a subscale for integrated regulation, which is a type of extrinsic motivation outlined in SDT. In fact, after the onset of the current study, a revised SMS was published (SMS-II, Pelletier, Rocchi, Vallerand, Deci, \& Ryan, 2013) which does include the integrated regulation subscale and may therefore be a better tool for measuring athletes' motivational regulations. Finally, all of the basketball players who participated in the study were competing for colleges and universities in the Midwest, so it is not known whether these results would generalize to other regions.

Motivation in sport is by no means a new area of research, yet there is still much to be discovered about the topic, especially as it relates to NCAA Division III athletes. For instance, as scholarships have been the focus of external rewards in Division I athletics, future research should identify the major external rewards in Division III sports, as well as any gender differences in the amount and perceived importance of both actual and perceived external rewards. Likewise, future research should seek to identify factors besides gender and playing status that might influence motivational regulations and goal orientation (i.e., team vs. individual sports, open vs. closed, position, etc.). In addition, a qualitative approach could be used to identify the specific motives, not just the sources of motivational regulations, for different types of athletes. For example, perhaps benchwarmers play for mainly social reasons whereas starters tend to play for more competency-based reasons. Finally, a longitudinal study would be useful to determine whether motivational regulations and goal orientation tend to impact playing status or if achieving a certain playing status influences motivational regulations and goal orientation.

\subsection{Conclusions}

Overall, the current study suggests that coaches and sport psychologists should not take a "one size fits all" approach to motivation in sport. Rather, it is a complex construct in which differences, such as gender and playing status, must be 
considered in order to find the best approach to enhance motivation and possibly improve performance. Similarly, a comprehensive understanding of motivation can only be gained through the use of multiple theoretical frameworks, such as SDT and AGT. Based on the benefits of IM and task goal separately, as well as the relationship between the two constructs, coaches should use practices aimed at enhancing their athletes' IM, as well as creating a task-oriented motivational climate.

\section{References}

Abrahamsen, F.E., Roberts, G.C., \& Pensgaard, A.M. (2008). Achievement goals and gender effects on multidimensional anxiety in national elite sport. Psychology of Sport \& Exercise, 9(4), 449-464.

Almagro, B.J., Sáenz-López, P, \& Moreno, J.A. (2010). Prediction of sport adherence through the influence of autonomy-supportive coaching among Spanish adolescent athletes. Journal of Sports Science and Medicine, 9(1), 8-14.

Ames, C.A. (1992). Classroom: Goals, structures, and student motivation. Journal of Educational Psychology, 84(3), 261-271.

Amorose, A.J. \& Anderson-Butcher, D. (2007). Autonomy-supportive coaching and self-determined motivation in high school and college athletes: A test of self-determination theory. Psychology of Sport \& Exercise, 8(5), 654-670.

Anderson, D.M. \& Dixon, A.W. (2009). Winning isn't everything: Goal orientation and gender differences in university leisure-skills classes. Recreational Sports Journal, 33(1), 54-64.

Bakirtzoglou, P. \& Ioannou, P. (2011). Goal orientations, motivational climate and dispositional flow in Greek secondary education students participating in physical education lesson: Differences based on gender. Physical Education and Sport, 9(3), 295-306.

Banack, H.R., Sabiston, C.M., \& Bloom, G.A. (2011). Coach autonomy support, basic need satisfaction, and intrinsic motivation of Paralympic athletes. Research Quarterly for Exercise and Sport, 82(4), 722-730.

Billings, A.C., \& Eastman, S. (2003). Framing identities: Gender, ethnic, and national parity in network announcing of the 2002 Winter Olympics. Journal of Communication, 53(4), 569-586.

Blegen, M.D., Stenson, M.R., Micek, D.M., \& Matthews, T.D. (2012). Motivational differences for participation among championship and non-championship caliber NCAA Division III football teams. Journal of Strength and Conditioning Research, 26(11), 2924-2928.

Braithwaite, R., Spray, C.M., \& Warburton, V.E. (2011). Motivational climate interventions in physical education: A meta-analysis. Psychology of Sport \& Exercise, 12(6), 628-638.

Chantal, Y., Guay, F., Dobreva-Martinova, T., \& Vallerand, R.J. (1996). Motivation and elite performance: An exploratory investigation with Bulgarian athletes. International Journal of Sport Psychology, 27(2), $173-182$.

Chin, N-S., Khoo, S., Low, W-Y. (2012). Self-determination and goal orientation in track and field. Journal of Human Kinetics, 33, 151-171. doi:10.2478/v10078-012-0054-0

Cremades, J.G., Flournoy, B., \& Gomez, C.B. (2012). Scholarship status and gender differences in motivation among U.S. collegiate track and field athletes. International Journal of Sports Science \& Coaching, 7(2), 333-344.

Cumming, J., Hall, C., Harwood, C. \& Gammage, K. (2002). Motivational orientations and imagery use: A goal profiling analysis. Journal of Sports Sciences, 20(2), 127-136.

Deci, E.L. \& Ryan, R.M. (1985). Intrinsic motivation and self-determination in human behavior. New York: Plenum.

Duda, J.L. (1989). Relationship between task and ego orientation and the perceived purpose of sport among high school athletes. Journal of Sport \& Exercise Psychology, 11(3), 318-335.

Duda, J.L., \& Whitehead, J. (1998). Measurement of goal perspectives in the physical domain. In J.L. Duda (Ed.), Advances in sport and exercise psychology measurement (pp. 21-48). Morgantown, WV: FIT.

Fenton, S.A.M., Duda, J.L., Quested, E., \& Barrett, T. (2014). Coach autonomy support predicts autonomous motivation and daily moderate-to-vigorous physical activity and sedentary time in youth sport participants. Psychology of Sport and Exercise, 15(5), 453-463.

Fortier, M.S., Vallerand, R.J., Briére, N.M., \& Provencher, P.J. (1995). Competitive and recreational sport structures and gender: A test of their relationship with sport motivation. International Journal of Sport Psychology, 26(1), 24-39.

Gano-Overway, L. A., \& Ewing, M. E. (2004). A longitudinal perspective of the relationship between

perceived motivational climate, goal orientations, and strategy use. Research Quarterly for Exercise and Sport, 75(3), 315-325.

Gill, D., Kelley, B., Martin, J. \& Caruso, C. (1991). A comparison of competitive-orientation measures. Journal of Sport \& Exercise Psychology, 13(3), 266-280.

Gillison, F., Osborn, M., Standage, M., \& Skevington, S. (2009). Exploring the experience of introjected regulation for exercise across gender in adolescence. Psychology of Sport and Exercise, 10(3), 309-319. 
Grappendorf, H., Henderson, A., Sanders, S., \& Peel, J. (2009). Is it equitable online? The media coverage of the 2007 NCAA Division I basketball tournament on foxsports.com. The SMART Journal, 5(1), 30-42.

Hanrahan, S.J., \& Biddle, S.J.H. (2002). Measurement of achievement orientations: Psychometric measures, gender, and sport differences. European Journal of Sport Science, 2(5), 1-12.

Hanrahan, S.J., \& Cerin, E. (2009). Gender, level of participation, and type of sport: Differences in achievement goal orientation and attributional style. Journal of Science and Medicine in Sport, 12(4), 508-512.

Li, F., Harmer, P., \& Acock, A. (1996). The Task and Ego Orientation in Sport Questionnaire: Construct equivalence and mean differences across gender. Research Quarterly for Exercise and Sport, 67(2), 228-238.

Lochbaum, M.R., Bixby, W.R., \& Wang, C.K.J. (2007). Achievement goal profiles for self-report physical activity participation: Differences in personality. Journal of Sport Behavior, 30(4), 471-490.

Mageau, G.A. \& Vallerand, R.J. (2003). The coach-athlete relationship: a motivational model. Journal of Sports Sciences, 21(11), 883-904.

Moreno-Murcia, J.A., Sicilia, A., Cervelló, E., Huéscar, E., \& Dumitru, D.C. (2011). The relationship between goal orientations, motivational climate and self-reported discipline is physical education. Journal of Sports Science and Medicine, 10(1), 119-129.

National Collegiate Athletic Association (2008). The student-athlete perspective of the college experience. Findings of the NCAA GOALS and SCORE studies. Retrieved from https://www.ncaa.org/sites/default/files/The\%20StudentAthlete\%20Perspective\%20of\%20the\%20College\%20Experience.pdf

National Collegiate Athletic Association (2014). NCAA sport sponsorship and participation rates report: 1981-1982 - 2013-2014. Retrieved from http://www.ncaapublications.com/productdownloads/PR1314.pdf

Newton, M., Duda, J.L., \& Yin, Z. (2000). Examination of the psychometric properties of the Perceived Motivational Climate in Sport Questioonnaire-2 in a sample of female athletes. Journal of Sports Sciences, 18(4), 275-290.

Nicholls, J.G. (1989). The Competitive Ethos and Democratic Education. Cambridge, MA: Harvard University Press.

Ntoumanis, N. (2001). Empirical links between achievement goal theory and self-determination theory in sport. Journal of Sports Sciences, 19(6), 397-409.

Nunnally, J.C., \& Bernstein, I.H. (1994). Psychometric theory ( $3^{\text {rd }}$ ed.). New York: McGraw-Hill.

Pelletier, L., Fortier, M., Vallerand, R., Tuson, K., Brière, N., \& Blais, M. (1995). Toward a new measure of intrinsic motivation, extrinsic motivation, and amotivation in sports: The sport motivation scale (SMS). Journal of Sport and Exercise Psychology, 17(1), 35-54.

Pelletier, L., Rocchi, M.a., Vallerand, R.J., Deci, E.L., \& Ryan, R.M. (2013). Validation of the revised sport motivation scale (SMS-II). Psychology of Sport and Exercise, 14(3), 329-341.

Pelletier, L., Vallerand, R.J., \& Sarazin, P. (2007). The revised six-factor Sport Motivation Scale (Mallett, Kawabata, Newcombe, Otero-Forero, \& Jackson, 2007): Something old, something new, and something borrowed. Psychology of Sport \& Exercise, 8(5), 615-621. doi:10.1016/j.psychsport.2007.03.006

Petlichkoff, L.M. (1993a). Group differences on achievement goal orientations, perceived ability, and level of satisfaction during an athletic season. Pediatric Exercise Science, 5(1), 12-24.

Petlichkoff, L.M. (1993b). Relationship of player status and time of season to achievement goals and perceived ability in interscholastic athletes. Pediatric Exercise Science, 5(3), 242-252.

Roberts, G.C. (2012). Motivation in sport and exercise from an achievement goal theory perspective: After 30 years, where are we? In G.C. Roberts \& D.C. Treasure (Eds.), Advances in Motivation in Sport and Exercise (3 ${ }^{\text {rd }}$ ed.). Champaign, IL: Human Kinetics.

Rotella, R.J. \& Newburg, D.S. (1989). The social psychology of the benchwarmer. The Sport Psychologist, 3(1), 4862.

Ruiz-Juan, F. \& Sancho, A.Z. (2012). Predictor variables of motivation on master athletes. Journal of Human Sport \& Exercise, 7(3), 617-628.

Ryan, E.D. (1977). Attribution, intrinsic motivation, and athletics. In L.I. Gedvilas \& M.E. Kneer (Eds.), Proceedings of the NCPEAM/NAPECW National Conference (pp. 346-353). Chicago: University of Illinois at Chicago.

Ryan, E.D. (1980). Attribution, intrinsic motivation, and athletics: A replication and extension. In C.H. Nadeau, W.R. Halliwell, K.M. Newell, \& G.C. Roberts (Eds.), Psychology of motor behavior and sport- 1979 (pp. 19-26). Champaign, IL: Human Kinetics.

Ryan, R.M. \& Deci, E.L. (2000). Intrinsic and extrinsic motivations: Classic definitions and new directions. Contemporary Educational Psychology, 25(1), 54-67.

Ryan, R.M. \& Deci, E.L. (2002). An overview of self-determination theory: An organismic-dialectical perspective. In E.L. Deci \& R.M. Ryan (Eds.), Handbook of self-determination research (pp.3-33). Rochester, NY: The University of Rochester Press. 
Satome, H., Harada, K., \& Nakamura, Y. (2012). The relationship between change in perceived motivational climate and change in goal orientations among Japanese ice hockey players. International Journal of Sports Science \& Coaching, 7(1), 81-88.

Spray, C.M, Wang, C.K.J., Biddle, S.J.H., \& Chatzisarantis, N.L.D. (2006). Understanding motivation in sport: An experimental test of achievement goal and self determination theories. European Journal of Sport Science, 6(1), 43-51.

Symons Downs, D., Savage, J.S., \& DiNallo, J.M. (2013). Self-determined to exercise? Leisure-time exercise behavior, exercise motivation, and exercise dependence in youth. Journal of Physical Activity and Health, 10(2), $176-184$.

Tabachnick, B. G., \& Fidell, L. S. (2001). Using multivariate statistics (4th ed.). New York: Allyn \& Bacon.

Vallerand, R.J. (1997). Toward a hierarchical model of intrinsic and extrinsic motivation. In M.P. Zanna (Ed.), Advances in experimental social psychology (Vol. 29, pp. 271-360). New York: Academic Press.

Vallerand, R.J., \& Losier, G.F. (1999). An integrative analysis of intrinsic and extrinsic motivation in sport. Journal of Applied Sport Psychology, 11(1), 142-169.

Walker, N.A. \& Bopp, T. (2011). The underrepresentation of women in the male-dominated sport workplace: Perspectives of female coaches. Journal of Workplace Rights, 15(1), 47-64.

Weiss, M.R. \& Frazer, K.M. (1995). Initial, continued, and sustained motivation in adolescent female athletes: A season-long analysis. Pediatric Exercise Science, 7(3), 314-329. 